\title{
A Landscape Approach for Detecting and Assessing Changes in an Area Prone to Desertification in Sardinia (Italy)
}

\author{
Francesca Giordano ${ }^{1,2}$ and Alberto Marini ${ }^{1}$ \\ ${ }^{1}$ TELEGIS Laboratory, Earth Sciences Department, University of Cagliari, Via Trentino 51, 09127 Cagliari, Italy \\ ${ }^{2}$ Department State of the Environment and Environmental Metrology, Italian Agency for Environmental Protection and \\ Technical Services (APAT), Via V. Brancati 48, 00144 Rome, Italy \\ Correspondence should be addressed to Francesca Giordano, fragisi@tin.it
}

Received 25 September 2007; Revised 6 December 2007; Accepted 17 March 2008

Recommended by Marco Gianinetto

Land degradation and desertification processes represent a serious problem in many areas of Sardinia (Italy), as in the Nurra region where urbanization, overgrazing, and fires have induced environmental degradation and rapid land-use change. In this study, using satellite remote sensing and geographical information system, landcover and landscape change dynamics were investigated. Comparing two Landsat-5 Thematic Mapper, it was possible to assess landcover transformations, and with the FRAGSTATS software it was possible to quantify the changes of landscape characteristics in the Nurra region over a 10-years period. The images were classified into seven landcover types, and a stepwise indicator approach was adopted. The results show a decrease in cropland and an increase of forestland and urban areas. The overall change was estimated to be about $2.5 \%$ of the total study area, with two most frequent landcover conversion types: cropland to urban areas and cropland to forestland.

Copyright $\odot 2008$ F. Giordano and A. Marini. This is an open access article distributed under the Creative Commons Attribution License, which permits unrestricted use, distribution, and reproduction in any medium, provided the original work is properly cited.

\section{INTRODUCTION}

In the last two centuries, the impact of human activities on the land has grown enormously, altering entire landscapes with important ecological consequences like biodiversity loss, deforestation, soil erosion, and desertification.

According to article 1 of the United Nations Convention to Combat Desertification (UNCCD) desertification is "land degradation in arid, semi-arid and dry sub-humid areas resulting from various factors, including climatic variations and human activities" [1]. Instead, land degradation is a reduction in the biological and economic productivity of terrestrial ecosystems, including soil, vegetation, and biota. Land degradation also disturbs the ecological, biogeochemical, and hydrological processes.

Before the presence of the man, natural processes shaped the landscape, but after the man came to Earth, Earth's face has changed. In the past two centuries, the impact of human agricultural, industrial, and extractive activities, combined with natural and human actions, induced climatic variations which led to land degradation on an unprecedented scale.
Due to its particular geographical position and its extreme climatic variations such as droughts and floods, Sardinia can be considered a representative area of the typical environmental problems of the Mediterranean basin. Desertification processes, in particular, represent a serious threat to many areas on the island where the impact of human activities on the environment is overlapped to the climatic stress. In the last decades, the urbanization along the coastal areas has strongly increased due to new tourist settlements and urban infrastructures. Not only urbanization but also the loss of fertile soils, massive water exploitation, overgrazing, and fires are the other important reasons for the environmental problems in the Nurra region, the northwestern part of the Island. Many scientific projects such as DesertNet [2], RIADE [3], and DesertWatch [4] have previously investigated this area with results demonstrating the high sensitivity to desertification of the area.

The objective of the present study was to detect, characterize, and quantify the changes in terms of landcover and landscape in an area sensitive to land degradation and desertification in the Nurra region. In the present study, 


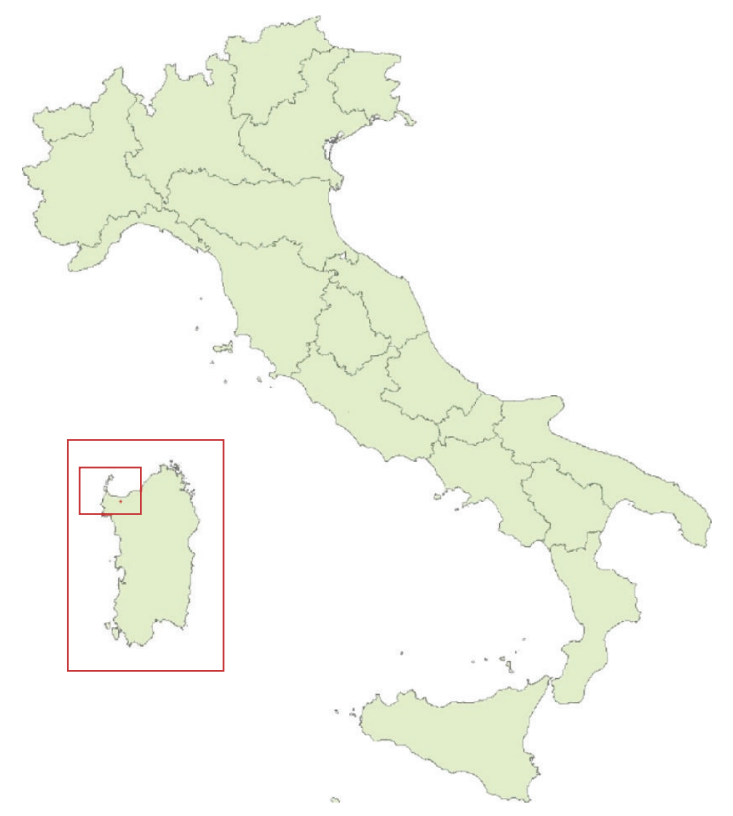

Figure 1: Nurra and town of Sassari in Sardinia (Italy).

remote sensing techniques were applied in order to analyze landcover change from 1990 to 2000 by Landsat Thematic Mapper TM images interpretation and to assess landscape structure change by using FRAGSTATS, a spatial pattern analysis program software package [5].

\section{STUDY AREA}

The study area (ca $40^{\circ} 43^{\prime} \mathrm{N}, 8^{\circ} 34^{\prime} \mathrm{E}$ ) is located in the north-western part of Sardinia (Italy) (see Figure 1) and covers four municipalities: Sassari, Alghero, Stintino, and Porto Torres. This area of about 88400 ha is characterized by a high geological and morphological complexity. The climate is typically Mediterranean dry-subhumid with abundant amount of rainfall during the autumn-winter period and a scarce amount of rainfall with very high temperature during the summer period. Mean annual precipitation values vary between $490 \mathrm{~mm}$ and $870 \mathrm{~mm}$. The area belongs to the phytoclimatic area of Lauretum.

As demonstrated from recent studies [6], the area is strongly sensitive to land degradation and desertification with more than half of the territory belonging to critical environmentally sensitive areas (ESAs) or "areas already highly degraded through past misuse, presenting a threat to the environment of the surrounding areas" [7].

\section{METHODS}

Two Landsat satellite Thematic Mapper TM images were selected over the study area. The first image was a Landsat5 Thematic Mapper of May 12, 1990, with seven spectral bands and a spatial resolution of $30 \mathrm{~m}$. The second one was a Landsat-5 Thematic Mapper of June 27, 2000. For the analysis of Landsat satellite images, ERDAS Imagine 8.5 software was used [8,9]. Landsat 5 TM of June 27, 2000 was used as a reference image to geo-reference the other image within acceptable limits ( $\mathrm{rms}=0.71$ pixels for the 1990 scene), and the nearest neighbour algorithm was used as the resampling method [10]. Atmospheric correction is not strictly necessary when postclassification change detection is the method selected for the analysis of changes. In this case, each image is individually classified and then the resulting maps are compared [11].

In this approach, supervised classification was used in order to perform a landcover map for each image. In this type of classification, the user selects the spectral signatures defined from recognized locations in the image or "training sample." The computer system then identifies the pixels with similar characteristics and assigns them to a class based on specific criteria. About 50 sample data were defined with help of ortophotos (scale $1: 10.000$ ) and available maps. These tools helped classify a seven-class legend: urban areas, forestland, shrubland, cropland, barren land, wetlands, and water bodies [12]. Supervised classification was then performed using the maximum likelihood method, in which a pixel with the maximum likelihood is classified to its corresponding class. The accuracy assessment showed that the overall accuracy of the landcover maps approached $88 \%$ for the 1990 image and $92 \%$ for the 2000 image. The existence of mixed pixels (pixels having more than one class in their footprint), in particular among vegetation classes, would require an analysis at a higher geometric resolution or a comparison with multitemporal data to exploit the phenological curves. This analysis would be useful in order to find if the classification accuracy could further improve. After performing the landcover maps, the next step was to overlay them and create a landcover change map (19902000).

In order to perform the landcover and landscape dynamics analysis of the study area, a stepwise indicator approach was used to measure the various aspects of landcover and landscape and their change [13-15].

Landcover maps represent the source of landcover indicators (1990 and 2000) and landscape metrics (1990 and 2000).

In particular, landcover indicators aimed at the evaluation of the extent of each landcover class in 1990 and in 2000 and measured the direction of change (increase/decrease) of each class during the study period.

Landscape metrics measure the spatial structure of landcover metrics in terms of composition (number, proportional frequency, and diversity of landscape elements within the landscape) and configuration (spatial position and distribution of the elements within the landscape). In order to calculate landscape metrics, landcover maps were converted into Grid format using ERDAS Imagine $[8,9]$ and introduced into the FRAGSTATS software [5].

In particular landscape metrics at class level, measuring the aggregate properties of the patches belonging to a single class or patch type, and landscape metrics at landscape level, measuring the aggregate properties of the entire patch mosaic, were performed.

Landcover change map (1990-2000) represents the source of landcover change indicators, which aim at the location of the areas of change and at the evaluation of the 
TABLE 1: Landcover areas per classes in the study area, 1990 and 2000.

\begin{tabular}{|c|c|c|c|c|c|c|}
\hline \multirow{2}{*}{ Class } & \multicolumn{2}{|c|}{ Area in 1990} & \multirow{2}{*}{ Class } & \multicolumn{2}{|c|}{ Area in 2000} & \multirow{2}{*}{ Direction of change } \\
\hline & ha & $\%$ & & ha & $\%$ & \\
\hline Cropland & $67.209,5$ & 76,0 & Cropland & $65.956,9$ & 74,6 & decrease \\
\hline Forestland & $8.246,4$ & 9,3 & Forestland & $9.088,6$ & 10,3 & increase \\
\hline Shrubland & $7.528,8$ & 8,5 & Shrubland & $7.487,8$ & 8,5 & - \\
\hline Urban areas & $4.033,2$ & 4,6 & Urban areas & $4.455,7$ & 5,0 & increase \\
\hline Barren & $1.064,2$ & 1,2 & Barren & $1.118,6$ & 1,3 & slight increase \\
\hline Wetlands & 230,3 & 0,3 & Wetlands & 251,9 & 0,3 & slight increase \\
\hline Water bodies & 75,9 & 0,1 & Water bodies & 28,8 & 0,0 & decrease \\
\hline Total & $88.388,2$ & 100,0 & Total & $88.388,2$ & 100,0 & \\
\hline
\end{tabular}

TABLe 2: Landscape metrics at class level, 1990 and 2000.

\begin{tabular}{|c|c|c|c|c|c|c|c|c|}
\hline Class & $\begin{array}{l}\text { CA } \\
\text { (ha) }\end{array}$ & $\begin{array}{c}\text { PLAND } \\
(\%)\end{array}$ & $\begin{array}{l}\mathrm{NP} \\
(\#)\end{array}$ & $\begin{array}{c}\text { PD } \\
(\# / 100 \text { ha })\end{array}$ & $\begin{array}{c}\text { AREA_MN } \\
\text { (ha) }\end{array}$ & $\begin{array}{c}\text { SHAPE_AM } \\
\text { (ha) }\end{array}$ & $\begin{array}{c}\text { PROX_MN } \\
(\mathrm{m})\end{array}$ & $\begin{array}{l}\text { IJI } \\
(\%)\end{array}$ \\
\hline \multicolumn{9}{|c|}{1990} \\
\hline Cropland & 67210 & 29,2 & 1830 & 0,8 & 36,8 & 21,8 & 56710 & 63,7 \\
\hline Forestland & 8246 & 3,6 & 5140 & 2,2 & 1,6 & 5,8 & 71,2 & 54,9 \\
\hline Urban areas & 4033 & 1,8 & 1775 & 0,8 & 2,3 & 5,9 & 112,2 & 33,4 \\
\hline \multicolumn{9}{|c|}{2000} \\
\hline Cropland & 65957 & 28,7 & 1660 & 0,7 & 39,7 & 17,6 & 66550 & 69,8 \\
\hline Forestland & 9088 & 3,9 & 4190 & 1,8 & 2,2 & 7,3 & 212,2 & 61,0 \\
\hline Urban areas & 4455 & 1,9 & 689 & 0,3 & 6,5 & 5,9 & 301,3 & 48,0 \\
\hline
\end{tabular}

extent of changes for the total study area and for each landcover class. These indicators measure also the landcover transition direction and the gains and losses for each class during the study period.

The entire set of landcover and landscape indicators has been setup in order to answer the following questions. Where are the landcover changes (location)? Which is the magnitude of landcover change (extension)? Which is the direction of landcover change (direction)? Which are the spatial characteristics of landscape change (structure)?

\section{RESULTS}

\subsection{Landcover indicators}

Once the classification of each image was performed, and the landcover maps for each period of study were obtained, the first step was to quantify each landcover class extension over the total area (see Table 1).

Cropland is largely the dominant landcover type in the study area in both cases, followed by forestland, shrubland, and urban areas. In particular during the period from 1990 to 2000 , cropland decreased from $76 \%$ to $74.6 \%$, while forestland and urban areas increased in area (from 9.3\% to $10.3 \%$ and from $4.6 \%$ to $5 \%$, resp.) and shrubland maintained the same dimensions. Furthermore, a sharp decrease of water bodies occurred.

The increase of urban areas, due to the continuous urbanization process in the Nurra region during the last years, is not a direct cause of the decrease in the area of water bodies. The variation in water bodies is probably due to the increase of riparian vegetation, with a consequent silting up of the shallow waters, in particular along the coast of the Baratz lake.

\subsection{Landscape indicators at class level}

Landcover maps were the source for the landscape metrics computation at class level and at landscape level by means of FRAGSTATS software [5].

Table 2 shows the most relevant landscape metrics performed at class level for the entire study area and for the most changing classes (cropland, forestland, and urban areas) [16-18]. For the analysis and the comprehension of landscape metrics at class level, it is advisable not to analyze just a landscape metric but rather a set of metrics to better understand and describe the dynamics of ecosystems and landscape structures.

Cropland in the study area represents the major class of the landscape. The study shows a decrease of cropland in terms of the percentage of landscape (PLAND, proportional abundance of each patch type in the landscape), the number of patches (NP, extent of subdivision or fragmentation of the patch type), and the patch density (PD, number of patches on a per unit area) during the period from 1990 to 2000. Instead, the area weighted mean shape index (SHAPE_AM, mean patch shape complexity weighted by patch area) shows the highest values both in 1990 and 2000 for cropland in the study area and shows a decline during the study period from 21.8 to 17.6 indicating a reduction in the shape complexity. Shape complexity relates to the geometry of 
TABLE 3: Landscape metrics at landscape level, 1990 and 2000.

\begin{tabular}{cccccccccccc}
\hline Year & $\begin{array}{c}\text { NP } \\
(\#)\end{array}$ & $\begin{array}{c}\text { PD } \\
(\# / 100 \mathrm{ha})\end{array}$ & $\begin{array}{c}\text { LPI } \\
(\%)\end{array}$ & $\begin{array}{c}\text { AREA_MN } \\
(\mathrm{ha})\end{array}$ & $\begin{array}{c}\text { SHAPE_AM } \\
(\mathrm{ha})\end{array}$ & $\begin{array}{c}\text { PROX_MN } \\
(\mathrm{m})\end{array}$ & $\begin{array}{c}\text { IJI } \\
(\%)\end{array}$ & $\begin{array}{c}\text { PR } \\
-\end{array}$ & $\begin{array}{c}\text { SHDI } \\
-\end{array}$ & $\begin{array}{c}\text { SHEI } \\
-\end{array}$ \\
\hline 1990 & 11960 & 5,2 & 28,4 & 7,4 & 17,9 & 8750 & 55,9 & 7 & 0,85 & 0,44 \\
2000 & 9840 & 4,3 & 27,5 & 9,0 & 14,6 & 11390 & 61,1 & 7 & 0,89 & 0,46 \\
\hline
\end{tabular}

patches whether they tend to be simple and compact or irregular and convoluted.

In regards to the forestland during the period 1990 2000, the number of patches (NP) decreased from 5140 to 4190 , the mean patch area (AREA_MN, average size of patches) increased from 1.6 to 2.2 , and the mean proximity index (PROX_MN, average proximity index for all patches in a class) increased from 71.2 to 212.2. This indicates that patches of the same type increasingly occupy the neighborhood between forested patches, which is defined by $300 \mathrm{~m}$, and those patches have become closer and more contiguous in distribution. In this sense, the forested landscape has become less fragmented [19].

The analysis of urban areas indicated that the number of patches (NP) significantly decreased from 1775 to 689, while the mean patch area (AREA_MN) increased from 2.3 to 6.5 and the class area (CA, total area of all patches per class) increased from 4033 to 4455 . This combination of results shows that new urban buildings generally occur in the voids of the core or adjacent to existent urban patches indicating that urban areas grow in a concentrated way [20]. Finally, the increase of the mean proximity index (from 112 to 301) and of the interspersion and juxtaposition index (from 33,4 to 48,0 ) of urban class shows a more uniform landscape configuration. The first index indicates an increase in the proximity of urban patches, which has become closer and more contiguous in distribution. As for the second index, it measures an increase of the interspersion (or intermixing of patch types) of urban patches (more equally adjacent to each other).

\subsection{Landscape indicators at landscape level}

Table 3 shows the most relevant landscape metrics performed at landscape level for the study area.

As seen in Table 3, during the decade 1990-2000 the patch number (NP) in the study area decreased (from 11960 to 9840 ), and the mean patch area (AREA_MN) increased (from 7.4 to 9.0), showing a trend towards an increasingly large-grained landscape.

Shannon's diversity (SHDI) and evenness (SHEI) indices both became greater, showing that the landscape heterogeneity and evenness slightly increased. Shannon's diversity index is, in fact, a popular measure of diversity in community ecology, applied here to landscapes as a measure of the equitability of the number of patch types and of the proportional distribution of area among patch types. Shannon evenness index is another popular diversity measure borrowed from community ecology, indicating the evenness of the distribution of area among the different patch types [5].
The spatial context of landscape patches also had some changes. For instance, the mean proximity index became greater (from 8750 to 11390 ) displaying that the spatial distribution of patches became more continuous. In addition, the increase of interspersion and juxtaposition index (from 55.9 to 61.1 ), together with the increase of mean proximity index, indicated a more uniform landscape configuration.

\subsection{Landcover change indicators}

From the overlaying of the two landcover maps, a landcover change area (1990-2000) was estimated to be about $2.5 \%$ of the total study area. Now, we do not have enough ground information to be able to rule out errors in the classification. Considering that there is $8 \%-12 \%$ error in classification accuracy, we expect to improve the analysis through further ground points all over the changed areas in order to increase the significance of the result.

Two landcover conversions were the most frequent in the study area: conversion from cropland to urban areas (45.7\%) and conversion from cropland to forestland (44.5\%). In Sassari, Alghero, and Stintino municipalities, the overlay of the landcover change map within the administrative limits showed that the percentage of landcover was mainly composed by cropland followed by forestland, shrubland, and urban areas. The only difference found was in Porto Torres, where the landscape was dominated by cropland followed by urban areas, which represented the second landscape class in terms of spatial extension.

The major landcover changes occurred in the Sassari municipality (3\%), followed by the Alghero municipality $(1.7 \%)$ and finally by the Porto Torres and Stintino municipalities (1.2\%). In particular, the conversion from cropland to urban areas represented $52 \%$ of the changes in the Sassari area, $26.3 \%$ of changes in the Alghero area, and $61.7 \%$ of the changes in the Porto Torres area and, in conclusion, $45.6 \%$ of the changes in the Stintino area were related to the conversion from cropland to forestland.

\section{CONCLUSIONS}

The analysis carried out showed that the landscape of the study area is dominated by cropland, followed by forestland and shrubland, and urban areas. During the study period (1990-2000) cropland decreased, while forestland and urban areas increased. The dynamics of change revealed that forested landscape has become less fragmented during the decade thus avoiding the breakup of natural areas into smaller and more isolated units. As for the urban areas, they showed growth in a concentrated way, as new urban 
buildings generally occurred in the voids of the core or adjacent to existent urban patches.

The overall landcover change in the area was estimated to be about $2.5 \%$ of the total study area, with two most frequent landcover conversion types:

(i) conversion from cropland to urban areas (45.7\%),

(ii) conversion from cropland to forestland (44.5\%).

The major landcover changes occurred in the Sassari municipality (3\%), followed by the Alghero municipality (1.7\%).

The present work describes the analysis performed in terms of landcover and landscape change by means of remote sensing and GIS techniques in an area prone to land degradation and desertification in Sardinia (Italy) during the period 1990-2000. For this purpose, a set of landcover and landscape indicators was setup, and a quantitative characterization of changes was performed. The combination of Landsat data, GIS, and FRAGSTATS software was generally helpful in providing techniques to monitor landcover and landscape evolution during the study period. The procedure adopted answered some important question about the changes that occurred in the area: Where are the changes? Which are the magnitudes of changes? Which are the directions of changes? Which are the spatial characteristics? Further research is needed in order to better understand the evolution of landcover and landscape in areas in which land degradation and desertification processes are occurring.

\section{REFERENCES}

[1] UNCCD (United Nations Convention to Combat Desertification), 1996. United Nations, 2008, http://www.unccd.int/.

[2] Desertwatch Project, 2008, http://www.desertnet.org/.

[3] Riade Project, 2008, http://www.riade.net/.

[4] DesertNet Project, 2008, http://dup.esrin.esa.it/desertwatch/.

[5] K. McGarigal, S. A. Cushman, M. C. Neel, and E. Ene, FRAGSTATS: Spatial Pattern Analysis Program for Categorical Maps. Computer Software Program, University of Massachusetts, Amherst, Mass, USA, 2002.

[6] A. Motroni, S. Canu, G. Bianco, and G. Loj, "Carta delle aree sensibili alla desertificazione (Environmentally sensitive areas to desertification, ESAs)," Servizio Agrometeorologico regionale per la Sardegna, April 2004.

[7] C. Kosmas, M. Kirkby, and N. Geeson, Eds., "The Medalus project Mediterranean desertification and land use. Manual on key indicators of desertification and mapping environmentally sensitive areas to desertification," EUR 18882, EC (European Community), Brussels, Belgium, 1999.

[8] ERDAS, ERDAS Field Guide, Revised and Expanded, ERDAS, Atlanta, Ga, USA, 5th edition, 2001.

[9] ERDAS, ERDAS IMAGINE Tour Guides, Erdas Imagine V8.5, ERDAS, Atlanta, Ga, USA, 2001.

[10] Z. Li, X. Li, Y. Wang, A. Ma, and J. Wang, "Land-use change analysis in Yulin prefecture, northwestern China using remote sensing and GIS," International Journal of Remote Sensing, vol. 25, no. 24, pp. 5691-5703, 2004.

[11] D. Lu, P. Mausel, E. Brondízio, and E. Moran, "Change detection techniques," International Journal of Remote Sensing, vol. 25, no. 12, pp. 2365-2407, 2004.

[12] W. G. Kepner, C. J. Watts, C. M. Edmonds, J. K. Maingi, S. E. Marsh, and G. Luna, "A landscape approach for detecting and evaluating change in a semi-arid environment," Environmental Monitoring and Assessment, vol. 64, no. 1, pp. 179-195, 2000.

[13] F. Herzog and A. Lausch, "Supplementing land-use statistics with landscape metrics: some methodological considerations," Environmental Monitoring and Assessment, vol. 72, no. 1, pp. 37-50, 2001.

[14] A. Lausch, "Assessment of landscape pattern and landscape functions by application of GIS and remote sensing," in Proceedings of the 3rd International Conference on Ecosystems and Sustainable Development (ECOSUD '01), Y. Villacampa, C. A. Brebbia, and J. L. Uso, Eds., vol. 10, pp. 367-376, WITPRESS, Alicante, Spain, June 2001.

[15] A. Lausch and H. Thulke, "The analysis of spatio-temporal dynamics of landscape structures," in Landscape Balance and Landscape Assessment, R. Kronert, U. Steinhardt, and M. Volk, Eds., pp. 113-136, Springer, Berlin, Germany, 2001.

[16] S. Weiers, M. Bock, M. Wissen, and G. Rossner, "Mapping and indicator approaches for the assessment of habitats at different scales using remote sensing and GIS methods," Landscape and Urban Planning, vol. 67, no. 1-4, pp. 43-65, 2004.

[17] Y.-C. Weng, "Spatiotemporal changes of landscape pattern in response to urbanization," Landscape and Urban Planning, vol. 81, no. 4, pp. 341-353, 2007.

[18] X. J. Yu and C. N. Ng, "Spatial and temporal dynamics of urban sprawl along two urban-rural transects: a case study of Guangzhou, China," Landscape and Urban Planning, vol. 79, no. 1, pp. 96-109, 2007.

[19] D. Geneletti, "Using spatial indicators and value functions to assess ecosystem fragmentation caused by linear infrastructures," International Journal of Applied Earth Observation and Geoinformation, vol. 5, no. 1, pp. 1-15, 2004.

[20] A. Bianchin and L. Bravin, "Defining and detecting changes in urban areas," International Archives of Photogrammetry Remote Sensing and Spatial Information Sciences, vol. 35, part 7, pp. 466-471, 2004. 

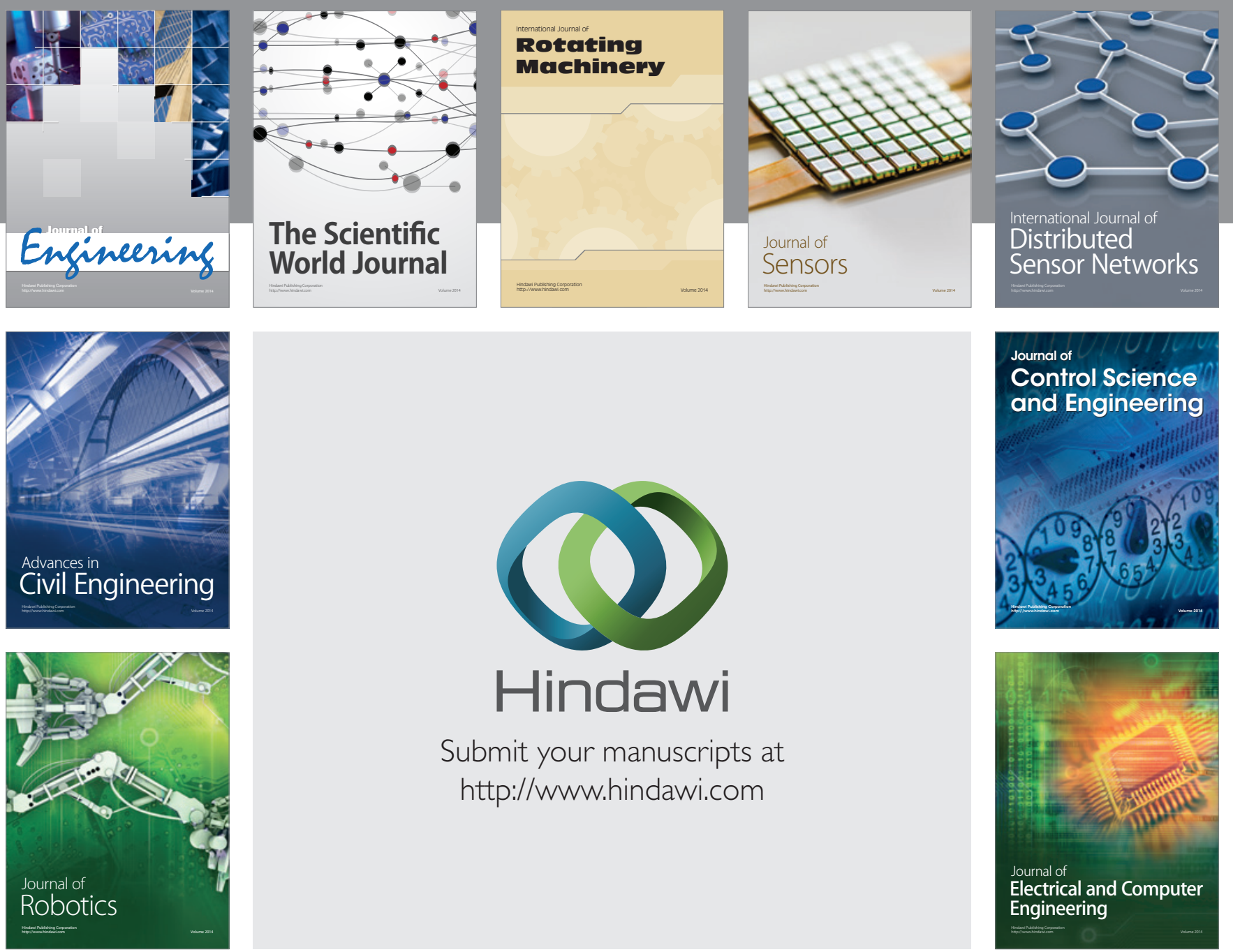

Submit your manuscripts at

http://www.hindawi.com
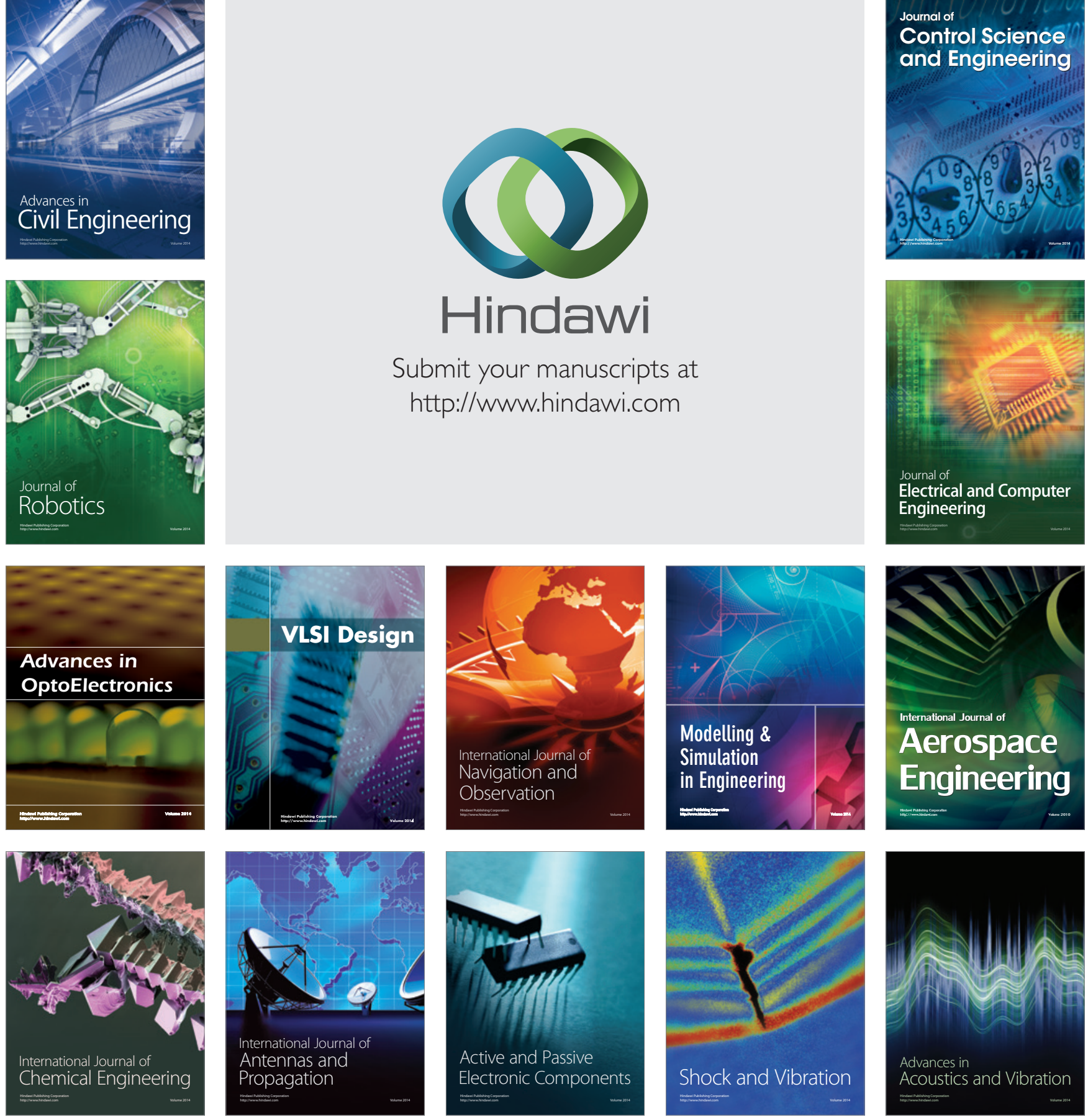